\title{
Effects of catalytic bed position on hydrogen production by methane decomposition
}

\author{
${ }^{1}$ Umair Sikander, ${ }^{* *}$ Suriati Sufian, ${ }^{1}$ KuZilati KuShaari, ${ }^{2}$ Fai Kait Chong \\ ${ }^{1}$ Chemical Engineering Department, Universiti Teknologi PETRONAS, \\ 32610, Bandar Seri Iskandar, Perak, Malaysia \\ ** Corresponding Author: suriati@utp.edu.my \\ ${ }^{2}$ Fundamental and Applied Sciences Department, Universiti Teknologi PETRONAS, \\ 32610 Bandar Seri Iskandar, Perak, Malaysia
}

\begin{abstract}
$\mathrm{CO}_{\mathrm{x}}$ free hydrogen can be produced by thermal decomposition of methane. Such process is carried out in a fixed bed catalytic reactor. Where heterogeneous catalytic reaction occur when methane come in contact with catalyst bed at a temperature range of $650-900^{\circ} \mathrm{C}$. In this work effect of different catalyst bed positions are investigated on the overall methane conversion to hydrogen. Experimental studies are carried out to in a Fixed Bed Reactor at $700^{\circ} \mathrm{C}$, by placing a catalyst bed of same porosity $\mu=0.2$ at $25 \%, 50 \%, 75 \%$ column height, and at top of reactor. It is found that same catalyst has shown different results when placed at different heights in reactor column. Highest methane conversion of $85 \%$ is found when catalyst bed is placed at $25 \%$ column height from bottom. It is found that for endothermic reactions like methane decomposition catalyst bed position has its significance due to its effects on process thermal conditions and on bed expansion by carbon deposition.
\end{abstract}

Keywords: Hydrogen, Methane Decomposition, Fixed Bed Reactor, Catalyst Bed.

\section{INTRODUCTION}

Recent increasing demand of $\mathrm{CO}_{\mathrm{x}}$ free hydrogen for fuel cell and other applications has motivated researchers to look for alternate resources of hydrogen production [1-5]. Lot of articles has been published recently on this topic [6-10]. Among various hydrogen production techniques direct thermo-catalytic decomposition of methane to produce pure hydrogen gas has shown most promising results [11-13]. In this process methane is decomposed directly to pure hydrogen and carbon, later being in the form of carbon nanofibers or nanotubes on the surface of catalyst [14]. As the process continues, amount of deposited carbon increases, filling the voids between catalyst particles to the point where it completely plugs the reactor [15]. Expansion of catalyst bed inside reactor is greatly affected by its position inside the reactor [16]. Catalyst bed position also has its effects on catalyst temperature, since temperature inside the reactor column is not consistent throughout the reactor length. Also reactant gases travels different distances before coming into contact with catalyst bed and are at different temperatures [17]. This $\Delta \mathrm{T}$ between reactant gas and catalyst bed affects the overall performance. In this aspect position of catalyst bed in fixed bed reactor greatly matters [18, 19]. While discussing catalyst sintering in a fixed bed reactor Blasco et al. have observed a change in coke 
deposition pattern at different positions of catalyst bed [20]. In another study, it is discussed in detail that thermal and kinetic behaviors are not consistent throughout the reactor length especially in the case of endothermic reactions [21]. Since, catalytic methane decomposition is an endothermic process [22], and all these factors are dependant over catalyst bed position, it is imperative to investigate the effects of catalyst bed position inside a reactor.

In this work conventional nickel supported over alumina catalyst is tested at different positions inside the reactor and its effects on \% conversion of methane are discussed.

\section{Synthesis of catalyst}

\section{METHODS AND MATERIALS}

$\mathrm{Ni}$ supported over alumina catalyst was synthesized by simple wet impregnation method [23]. Nickel nitrate $\left(\mathrm{NiNO}_{3} \cdot 6 \mathrm{H}_{2} \mathrm{O}\right)$ salt was impregnated over high surface area alumina (SA-6175), and was then dried for $14 \mathrm{~h}$ at $110^{\circ} \mathrm{C}$. The material was then calcined at $800^{\circ} \mathrm{C}$ for $3 h$.

\section{Methane decomposition tests}

Experiments of hydrogen production by methane decomposition were carried out in a stainless steel reactor. Total height of column reactor is $2 \mathrm{ft} 6$ in $(0.76 \mathrm{~m})$. Reactor column was enveloped in a high temperature furnace. K-type thermocouple is attached at the outer periphery of reactor column. Another movable K-type column is inserted inside the reactor in a thimble. Height of this thermocouple can be adjusted to measure inside reactor temperature at different positions. During each experiment $5 \mathrm{~g}$ of catalyst is used and rest of column is filled with non-reactive silica clay for proper heating of reactant gases. An online $\mathrm{HY}$-OPTIMA® $700 \mathrm{~B} \mathrm{H}_{2}$ gas analyzer is attached at the end to analyze the $\mathrm{H}_{2} \%$ in effluent gases.

Each experiment is carried out at a fixed temperature of $700^{\circ} \mathrm{C}$, and at weight hour space velocity of $8.5 \mathrm{l}_{\mathrm{CH} 4} \cdot \mathrm{g}_{\mathrm{cat}}{ }^{-1} \cdot \mathrm{h}^{-1}$. Before introducing methane, catalyst was in-situ activated by $99.999 \%$ pure hydrogen at $700^{\circ} \mathrm{C}$ for $3 \mathrm{~h}$. Column was then flushed with nitrogen gas. Methane decomposition reaction was carried out by passing $20 \%$ methanebalanced nitrogen $\left(20 \% \mathrm{CH}_{4} / 80 \% \mathrm{~N}_{2}\right)$ gas through the column. Reactant gas is injected at room temperature and at atmospheric pressure. Hydrogen produced is analyzed by the online HY-OPTIMA® gas analyzer.

Experiments were carried out by placing catalyst of same porosity of $\mu=0.2$ (calculated on the basis of bed density and particle density), at five different positions, at top of column, at $75 \%$ column height- position $\mathrm{A}$, at $50 \%$ column height- position $\mathrm{B}$, at $25 \%$ column height-position $\mathrm{C}$, and at bottom of column. Details and notations of these positions are shown in Figure 1. Each experiment was carried out with fresh catalyst sample and methane decomposition process was carried out continuously for $5 \mathrm{~h}$. In order to analyze significance of difference between methane \% conversions at different bed positions a statistical ONE-WAY ANOVA analysis is carried out. 


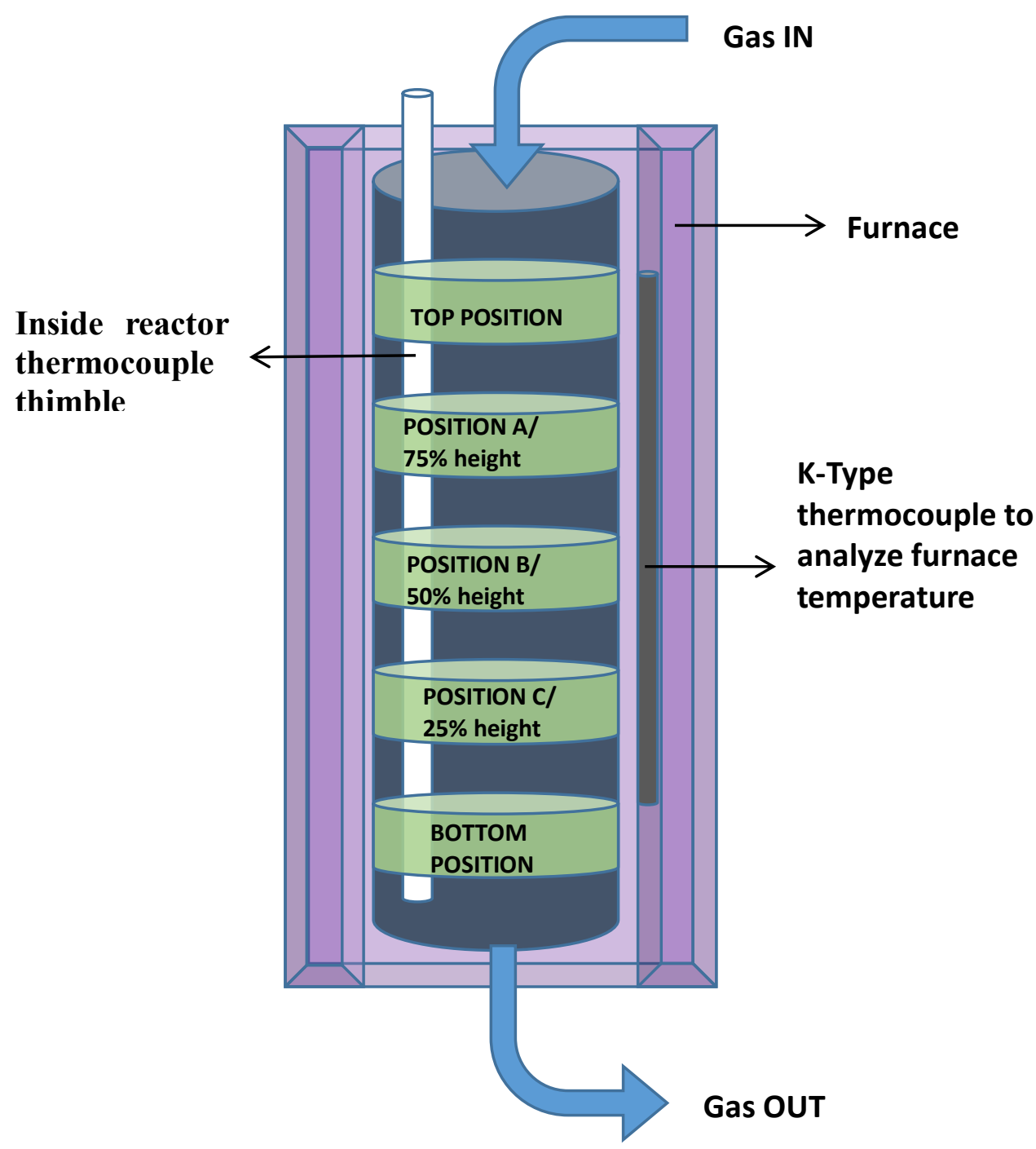

Figure 1: Schematic diagram of a fixed bed reactor

\section{RESULTS AND DISCUSSION}

Figure 2 shows the $\%$ conversion by volume of methane at $700^{\circ} \mathrm{C}$ over the same catalyst when placed at different positions. Different amount of conversion is observed at different positions of catalyst bed. Increasing amount of methane conversion is in following order, top $<$ bottom $<75 \%$ height $<50 \%$ height $<25 \%$ height. Amount of heat transfer along the reactor length is non uniform due to the difference in reactant temperature and flow profiles, as explained by Nijemeisland et. al [24]. Catalyst bed is normally operating at a low temperature compared to initial temperature before gas is introduced $[25,26]$. 
Comparison between catalyst bed temperature at different position prior to reactant gas flow and during gas flow is shown in Figure 3.

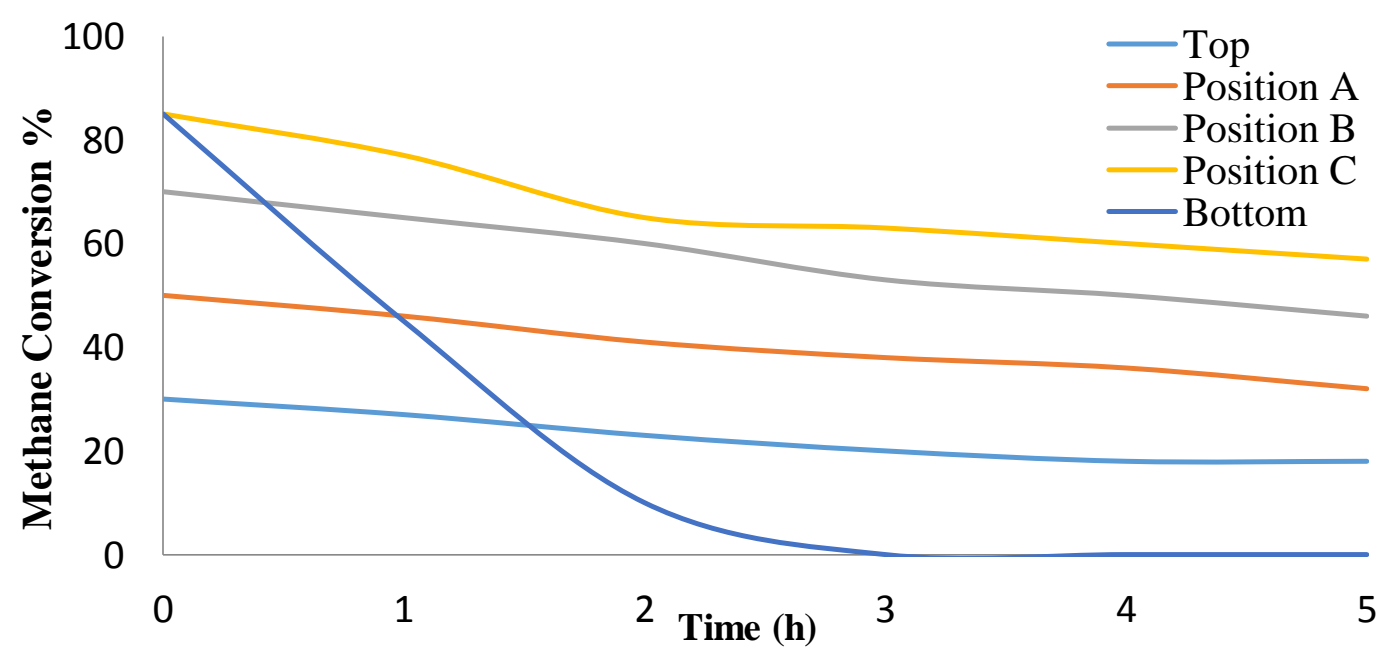

Fig 2: Methane conversion $\%$ at different positions for $5 \mathrm{~h}$

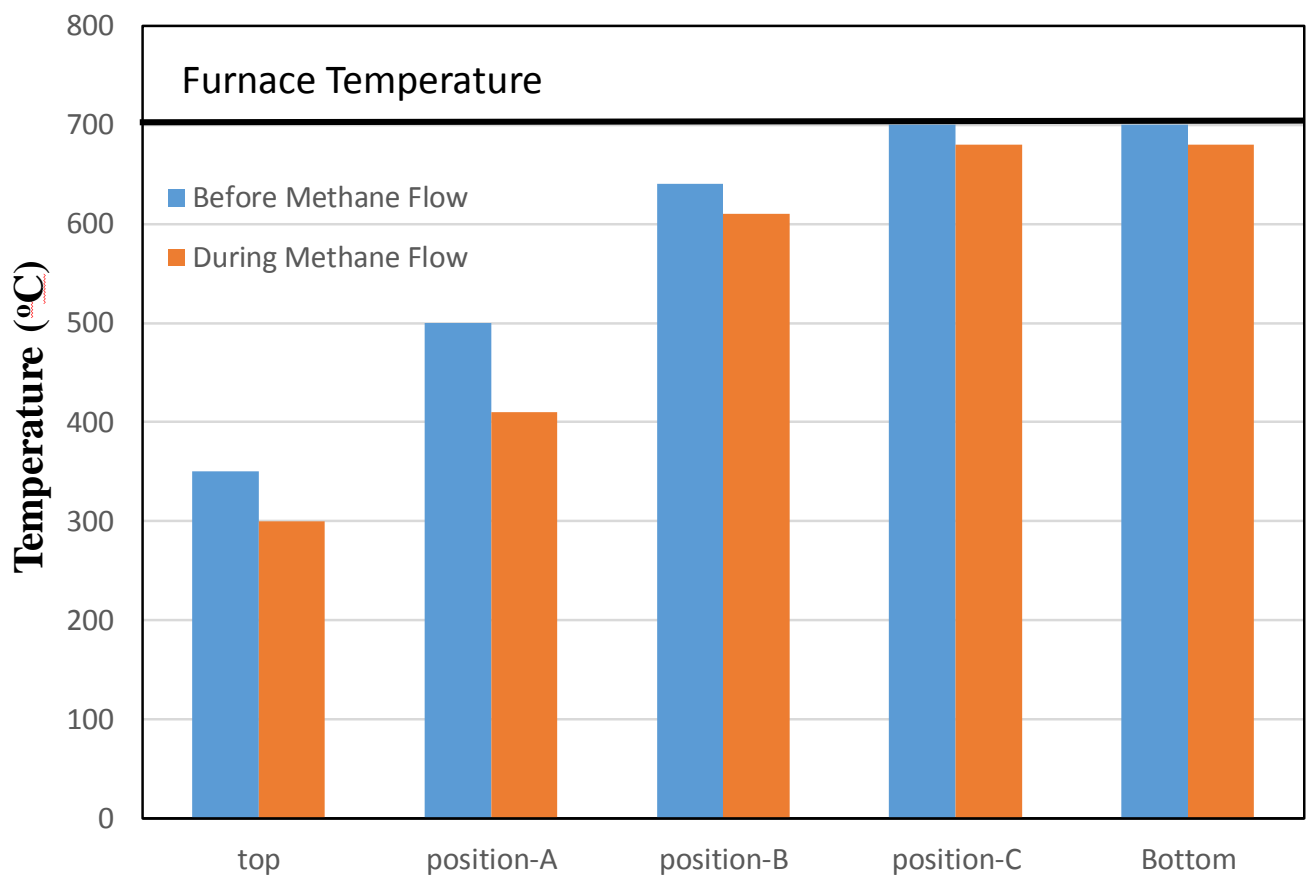

Figure 3. Catalyst bed temperature before and during flow of methane.

Since reactant gases are fed to the reactor at room temperature, they are at a relatively low temperature at the top of column height and its temperature increases as they pass through the column packing [27]. Very low conversion is observed when catalyst bed 
is placed at top of the reactor due to insufficient thermal energy. However, case is entirely different when catalyst bed is placed at bottom. Temperature observed at bottom of reactor is maximum when in operation (i.e. reactant gas is flowing through the column). Initially conversion for bottom and position- $\mathrm{C}$ is same as they are at same temperature but as the time passes \% conversion at bottom decreases rapidly to a full halt after two hours operation. This phenomenon is due to the unavailability of empty voids between catalyst particles at the bottom [28]. As the process continues the amount of deposited carbon on catalyst surface increase and fill the voids between catalyst particles, to the point where no voids for gas passage is available and catalyst bed is completely choked or clogged. Due to the catalyst bed position at bottom of reactor, expansion of bed is not possible, which is essential for the continuity of heterogeneous catalytic reaction in a fixed bed reactor [29]. As the process continues bulk density of bed increases and porosity decreases to zero, where no gas passage is available for methane [30].

At positions $\mathrm{A}, \mathrm{B}$, and $\mathrm{C}$, catalyst bed has shown good results with little variations in the overall conversion of methane. Among three positions, least amount of methane conversion is observed at position A. Again this phenomenon can be attributed to the high temperature difference between furnace temperature and bed temperature. Also it implies that sufficient amount of free space must be provided to reactant gases to approach a required temperature when come in contact with catalyst bed [31,32]. This also emphasize on the need of pre-heating treatment of reactant gases [33-35]. When a highly endothermic methane decomposition reaction occurs at position $\mathrm{A}$ there is a sudden decrease in bed temperature. There is no exothermic reaction to compensate as in the case of FischerTropch reactions [36]. Position-B is in the center of reactor and has shown relatively high and constant conversion of methane throughout the five hours operation. At this point catalyst bed temperature is in concurrence with furnace temperature when not under a reaction. However during reaction, catalyst bed temperature slightly decreases due to the endothermic nature of methane decomposition reaction. Statistical ONE-WAY ANOVA (F $(2,15)=14.14, p=0.0003)$ analysis is results are, $F(2,15)=14.14, p=0.0003$. Since $p-$ value is less than 0.05 , it is concluded that there is a statistically significant difference in $\%$ conversion at different bed positions. Best results are obtained when catalyst bed is placed at $25 \%$ column height. At position $\mathrm{C}$ which is the $25 \%$ height of column has shown the highest methane conversion to hydrogen. Temperature at this point is approximately same as of furnace temperature and a slight decrease is noted during the methane gas flow.

\section{CONCLUSIONS}

Hydrogen gas is successfully produced by catalytic decomposition of methane. It is found that appropriate catalyst bed position plays a vital role in catalyst bed expansion and effective heat transfer to the reactant gases. Catalyst bed when placed at different positions inside the reactor has shown statistically significant difference in results. Least amount of hydrogen is produced when catalyst bed is placed at the top of reactor. When placed at the bottom reactor is plugged after $2 \mathrm{~h}$. No plugging is found at Position-A, B and C. Highest methane conversion is recorded when catalyst bed is placed at position $\mathrm{C}(25 \%$ column height). 


\section{ACKNOWLEDGMENT}

We would like to acknowledge gratefully the financial support of this research by the YUTP grant 0153AA-E01, Malaysia.

\section{REFERENCES}

[1] HF Abbas and WMA. Wan Daud. Hydrogen production by methane decomposition: a review. International Journal of Hydrogen Energy.2010; 35(3):1160-1190.

[2] Špela Hajduk, Venkata D.B.C. Dasireddy,BlažLikozar, GoranDražić and Zorica Crnjak Orel. COx-free hydrogen production via decomposition of ammonia over $\mathrm{Cu}-\mathrm{Zn}$-based heterogeneous catalysts and their activity/stability. Applied Catalysis B: Environmental. 2017; 211:57-67.

[3] M Pudukudy,Z Yaakob, N Dahani,M S Takriff and N S Mat Hassan. Production of COx free hydrogen and nanocarbon via methane decomposition over unsupported porous nickel and iron catalysts. Journal of Cluster Science, 2017; 28(3):1579-1594.

[4] Bayat N, M Rezaei, and F Meshkani. Methane dissociation to CO x-free hydrogen and carbon nanofiber over Ni-Cu/Al 2 O 3 catalysts. Fuel. 2017; 195: 88-96.

[5] MM Noor, AP Wandel and T Yusaf. Air fuel ratio study for mixture of biogas and hydrogen on mild combustion. International Journal of Automotive and Mechanical Engineering.2014;10:2144-2154.

[6] Z He, J Fu, B Cheng, J Yu, and S Cao., Cu 2 (OH) 2 CO 3 clusters: Novel noble-metal-free cocatalysts for efficient photocatalytic hydrogen production from water splitting. Applied Catalysis B: Environmental.2017;205:104-111.

[7] A Carrero, JA. Calles, L García-Moreno and AJ. Vizcaíno, Production of Renewable Hydrogen from Glycerol Steam Reforming over Bimetallic Ni(Cu, Co, Cr) Catalysts Supported on SBA-15 Silica. Catalysts. 2017;7(2):55.

[8] R Kothari, V Kumar, VV Pathak, S Ahmad, O Aoyi and V.V.Tyagi. A critical review on factors influencing fermentative hydrogen production. Frontiers in bioscience (Landmark edition).2017; 22:1195.

[9] Muda, N. and M. Boosroh, Gasification of coal-petcoke blends in a pilot scale gasification plant. International Journal of Automotive and Mechanical Engineering.2013;8:1457.

[10] K I Hamada, MM Rahman, D Ramasamy, MM Noor and K Kadirgama. Numerical investigation of in-cylinder flow characteristics of hydrogenfuelled internal combustion engine. Journal of Mechanical Engineering and Sciences.2016;10(1):1782-1802.

[11] M Mahmoudi, J Dentzer, R Gadiou and A Ouederni. Evaluation of activated carbons based on olive stones as catalysts during hydrogen production by thermocatalytic decomposition of methane. International Journal of Hydrogen Energy. 2017;42(13):8712-8720. 
[12] Astrid Wolfbeisser, Gábor Kovács, Sergey M.Kozlov, Karin Föttinger, Johannes Bernardi, Bernhard Klötzer, Konstantin M.Neyman and Günther Rupprechter., Surface composition changes of CuNi-ZrO 2 during methane decomposition: An operando NAP-XPS and density functional study. Catalysis Today. 2017;283:134-143.

[13] Mondal KC and S.R. Chandran, Evaluation of the economic impact of hydrogen production by methane decomposition with steam reforming of methane process. International Journal of Hydrogen Energy.2014;39(18): 9670-9674.

[14] A E Awadallah, MS Mostafa, A A Aboul-Enein and S A Hanafi. Hydrogen production via methane decomposition over $\mathrm{Al} 2 \mathrm{O} 3-\mathrm{TiO} 2$ binary oxides supported Ni catalysts: Effect of Ti content on the catalytic efficiency. Fuel. 2014;129:68-77.

[15] S Fukuda, N Nakamura, J Monden and M Nishikawa. Experimental study of cracking methane by $\mathrm{Ni} / \mathrm{SiO} 2$ catalyst. Journal of nuclear materials. 2004; 329:1365-1369.

[16] GA Mauricio, RS Ruiza, FL Isunza, and C O Araiza, A simple approach to describe hydrodynamics and its effect on heat and mass transport in an industrial wall-cooled fixed bed catalytic reactor: ODH of ethane on a MoVNbTeO formulation. Chemical Engineering Journal. 2017;321:584-599.

[17] Nahavandi, M., Selective catalytic reduction(SCR) of NO by ammonia over V2O5/tio2 catalyst in a catalytic filter medium and honeycomb reactor: A kinetic modeling study. Brazilian Journal of Chemical Engineering. 2015; 32(4):875-893.

[18] L Kai;L JingLin;L XiaoSong;Z XiaoBing and Z AiMin.Warm plasma catalytic reforming of biogas in a heat-insulated reactor: Dramatic energy efficiency and catalyst auto-reduction. Chemical Engineering Journal. 2016; 288:671-679.

[19] Huff Jr, G.A. and C.N. Satterfield, Liquid accumulation in catalyst pores in a Fischer-Tropsch fixed-bed reactor. Industrial \& Engineering Chemistry Process Design and Development.1985;24(4):986-995.

[20] V Blasco,C Royo,A Monzón and J Santamaría, Catalyst sintering in fixedbed reactors: Deactivation rate and thermal history. AIChE journal.1992; 38(2):237-243.

[21] R. Burch, E M Crabb, G D Squire and S C Tsang, The importance of heterogeneous and homogeneous reactions in oxidative coupling of methane over chloride promoted oxide catalysts. Catalysis letters. 1989;2(4):249-256.

[22] Muradov N. Hydrogen via methane decomposition: an application for decarbonization of fossil fuels. International Journal of Hydrogen Energy, 2001; 26(11):1165-1175.

[23] A S A Al-Fatish, A A Ibrahim, A H Fakeeha, M A Soliman, M R H Siddiqui and A E Abasaeed Coke formation during $\mathrm{CO} 2$ reforming of $\mathrm{CH} 4$ over alumina-supported nickel catalysts. Applied Catalysis A: General. 2009; 364(1):150-155. 
[24] Nijemeisland, M. and A.G. Dixon, Comparison of CFD simulations to experiment for convective heat transfer in a gas-solid fixed bed. Chemical Engineering Journal. 2001;82(1)231-246.

[25] Bayat N, M. Rezaei, and F. Meshkani, Methane decomposition over Ni-Fe/Al $2 \mathrm{O} 3$ catalysts for production of $\mathrm{CO} \mathrm{x}$-free hydrogen and carbon nanofiber. International journal of hydrogen energy.2016;41(3):1574-1584.

[26] Pudukudy M, Z Yaakob and M S Takriff, Methane decomposition over Pd promoted $\mathrm{Ni} / \mathrm{MgAl} 2 \mathrm{O} 4$ catalysts for the production of $\mathrm{COx}$ free hydrogen and multiwalled carbon nanotubes. Applied Surface Science. 2015;356:13201326.

[27] Kolios G, J Frauhammer, and G Eigenberger. Autothermal fixed-bed reactor concepts. Chemical Engineering Science. 2000; 55(24):5945-5967.

[28] Dixon AG., M Nijemeisland, and E H. Stitt. Packed tubular reactor modeling and catalyst design using computational fluid dynamics. Advances in Chemical Engineering. 2006;31:307-389.

[29] Van Driesen, R.P., et al.. Control of bed expansion in expanded bed reactor. 1987, Google Patents.

[30] S H Sharif Zein, A R Mohamed, and P S T Sai, Kinetic studies on catalytic decomposition of methane to hydrogen and carbon over $\mathrm{Ni} / \mathrm{TiO} 2$ catalyst. Industrial \& engineering chemistry research. 2004;43(16):4864-4870.

[31] J Natarajan, T Lieuwen, and J Seitzman. Laminar flame speeds of H2/CO mixtures: effect of $\mathrm{CO} 2$ dilution, preheat temperature, and pressure. Combustion and Flame. 2007;151(1):104-119.

[32] J.Natarajan, Y Kochar, T.Lieuwen, and J.Seitzman. Pressure and preheat dependence of laminar flame speeds of $\mathrm{H} 2 / \mathrm{CO} / \mathrm{CO} 2 / \mathrm{O} 2 / \mathrm{He}$ mixtures. Proceedings of the Combustion Institute, 2009;32(1):1261-1268.

[33] Stilger, J.D., R.J. Martin, and M.R. Holst, Method and apparatus for recuperative heating of reactants in an reaction matrix. 1994, Google Patents.

[34] G Di Marcoberardino, F Sosio, G Manzolini and S Campanari., Fixed bed membrane reactor for hydrogen production from steam methane reforming: experimental and modeling approach. International Journal of Hydrogen Energy. 2015;40(24):7559-7567.

[35] S Abbas, V Dupont and T Mahmud, Modelling of $\mathrm{H}_{2}$ production in a packed bed reactor via sorption enhanced steam methane reforming process. International journal of hydrogen energy. 2017;42(30):18910-18921.

[36] Y N Wang, YY Xu, Y W Li, Y L Zhao and B J Zhang. Heterogeneous modeling for fixed-bed Fischer-Tropsch synthesis: reactor model and its applications. Chemical Engineering Science. 2003; 58(3):867-875. 